\title{
Costs of Drug Therapy in Patients with Ankylosing Spondylitis in Brazil
}

\author{
Marina Amaral de Ávila Machado · Felipe Ferre $\cdot$ Cristiano Soares de Moura $\cdot$ Alessandra Maciel Almeida \\ Eli Iola Gurgel Andrade $\cdot$ Mariângela Leal Cherchiglia $\cdot$ Francisco de Assis Acurcio
}

Received: May 17, 2016 / Published online: July 11, 2016

(C) The Author(s) 2016. This article is published with open access at Springerlink.com

\section{ABSTRACT}

Introduction: The Brazilian Public Health System offers free-of-charge drug treatment for ankylosing spondylitis (AS) to all Brazilian citizens. We report here the first population-based cohort study on patients with AS in Brazil. The aim of this study was to evaluate the costs of the tumour necrosis factor (anti-TNF) blockers and disease-modifying

Enhanced content To view enhanced content for this article go to http://www.medengine.com/Redeem/7FD4 F06066EEC4A8.

M. A. Á. Machado (凹) · F. Ferre · E. I. G. Andrade . M. L. Cherchiglia

College of Medicine, Federal University of Minas Gerais, Av. Prof. Alfredo Balena 190, Belo Horizonte 30130-100, MG, Brazil

e-mail: avila110@yahoo.com.br

C. S. Moura

Division of Clinical Epidemiology, McGill

University, 687 Pine Avenue West, V-Pavilion,

Montreal, QC, Canada

\section{A. M. Almeida}

Faculty of Medical Sciences of Minas Gerais,

Alameda Ezequiel Dias 275, Belo Horizonte, MG,

Brazil

\section{F. A. Acurcio}

Social Pharmacy Department, College of Pharmacy, Federal University of Minas Gerais, Av. Presidente Antônio Carlos 6627, Belo Horizonte, MG, Brazil antirheumatic drugs (DMARDs) that were used in the treatments of patients with AS in Brazil between March 2010 and September 2013.

Methods: A retrospective cohort study was performed using administrative databases. All patients with a diagnosis of AS who were aged 18 years or older and had been dispensed anti-TNF or DMARDs were included in the analysis. The cost analysis was carried out from the health system perspective, and the results were described as median monthly cost per capita and the annual cost over the study period.

Results: A search of the databases identified 1251 patients with AS who were treated during the study period, of whom $63.3 \%$ were male; the median age was 41 years. During the study period, $78.0 \%$ of patients initiated treatment with anti-TNF drugs and $22.0 \%$ with DMARDs. The median monthly cost per capita was US\$ 1650 for anti-TNF therapy and US\$ 25 for treatment with DMARDs. Among the anti-TNF drugs, therapy with etanercept was associated with the lowest cost per patient, followed by adalimumab and infliximab. No difference in monthly cost was observed in relation to gender and age. 
Conclusion: The cost per patient of treating AS in this study cohort was lower with etanercept than with adalimumab and infliximab. These results highlights the economic burden of treating patients with AS.

Keywords: Administrative claims data; Ankylosing spondylitis; Anti-TNF therapy; DMARDs; Drug cost

\section{INTRODUCTION}

Ankylosing spondylitis (AS) is a chronic rheumatic disease that affects the spine and sacroiliac joints, causing pain and inflammation. The global prevalence is between $0.1 \%$ and $1.4 \%$, and patients with active disease may present diminished physical functioning due the loss of lumbar mobility. As such, AS can also affect patient quality of life and participation in paid and unpaid work. It can also be an important component of healthcare costs $[1,2]$. The estimated annual indirect costs of AS were reported to range from $€ 3188$ to $€ 8862$ per patient in the Netherlands, France and Belgium, while the mean direct costs were $€ 2640$ per patient/year, with $13 \%$ of the costs related to drug expenditure [3]. In Brazil, the estimated direct cost of AS treatment was US\$21,091 per patient/year in 2011 for outpatients of a rheumatology service. Medications accounted for $96 \%$ of the cost, and $63 \%$ of patients were using the tumour necrosis factor blockers (anti-TNF) infliximab, etanercept or adalimumab [4]. The anti-TNF drugs are second-line treatment for AS and are used in patients whose disease activity remains high despite the use of nonsteroidal anti-inflammatory drugs (NSAIDs). Other AS therapies include disease-modifying antirheumatic drugs (DMARDs), such as sulfasalazine and methotrexate, for patients with peripheral arthritis [5, 6]. Following the introduction and wide-spread use of anti-TNF agents in clinical practice, the drug costs have increased and become the most important driver of direct costs in the management of AS [7].

In Brazil, patients with a diagnosis of AS have access to free-of-charge medical care and drug therapy through the Brazilian Public Health System (SUS). The anti-TNF agents have been available since March 2010 through the Specialised Component of Pharmaceutical Service. The Brazilian health system is a complex network of complementary and competitive services that form a public-private mix. The SUS is based on principles of universality, integrality and equity, while health care is also provided in the context of liberal practices to a limited segment of the population, usually those with higher purchasing power. The SUS covers physician visits, hospitalisations and medication and spends $50 \%$ of its total allotted national health expenditure ( $8 \%$ of the Brazilian gross domestic product in 2013). Approximately $25 \%$ of Brazilians have private health insurance, which does not preclude them from also using the services provided by the SUS, especially for high-cost procedures and medicines that may not be covered by the private insurance plans [8]. To the best of our knowledge, no population-based cohort studies on drug cost in the context of the SUS have been performed. The aim of this study was to describe the drug utilisation pattern and the cost for anti-TNF and DMARD therapies in AS patients in Brazil between March 2010 and September 2013. 


\section{METHODS}

We performed a retrospective cohort study using data obtained from SUS in Minas Gerais $(\mathrm{MG})$, a state located in the southeast of Brazil, with approximately 20 million inhabitants (10\% of Brazilian population). We used the Authorisation of High Complexity Procedures of the Outpatient Information System (APAC/ SIA) database that records pharmacy claims of the Specialised Component of Pharmaceutical Service. The inclusion criteria were patients (1) identified with AS based on ICD-10 codes M45, M46.9, and M46.8, (2) $\geq 18$ years of age and (3) who had been dispensed anti-TNF agents (adalimumab, etanercept or infliximab) or DMARDs (sulfasalazine or methotrexate) at least once between March 2010 and June 2013 and then followed up until September 2013. We considered these patients as new users, since in the context of SUS the anti-TNF agents become available for the treatment of AS in March 2010. There was a possibility that some patients received medication through the private system prior to cohort entry, but this information was not available for analysis.

For each patient we retrieved information on gender, age (at the time cohort entry), region of residence and income per capita. This latter variable was obtained from the linkage between the postcode recorded in the APAC/SIA database and the census tracts from 2010 Brazilian census and allowed us to classify study patients into income categories according to Brazil Government's criterion Brasil [Governo Federal. Presidência da República. Secretaria de Assuntos Estratégicos. Perguntas e respostas sobre a definição da classe média. (citado 2014 out 15). Disponível em: http://www.sae.gov.br/ site/?p=13431].

We performed a cost analysis from the health system perspective and included the total cost on drugs, recorded in the APAC/SIA database. We calculated both annual and monthly cost per calendar year during the study period, as well as the median monthly cost per capita. The cost was stratified by drug, gender and age. The prices of anti-TNF agents, which are purchased by the Brazilian Ministry of Health, were searched for in the Integrated System of Administration of General Services (SIASG) through the Health Pricing Database. The prices of DMARDs, which are purchased by the State Office of Health of Minas Gerais, were searched for in the Online Portal of Products of Minas Gerais. The prices were adjusted to January 2016 based on the National Consumer Price Index (IPCA-IBGE) and are presented in U.S. dollars (January 2016).

We calculated frequency distributions for the categorical variables and mean and standard deviation (SD) or median and interquartile range (IQR) for the continuous variables. We applied the non-parametric Mann-Whitney and Kruskal-Wallis tests for comparisons and a significance level of $5 \%$ was adopted. The analyses were performed using SAS version 9.4 for UNIX (SAS Institute Inc., Cary, NC). The research protocol of the study was approved by the Research Ethics Committee of the Federal University of Minas Gerais, Brazil (ETIC 0069.0.203.000-11).

\section{RESULTS}

A total of 1251 patients with at least one dispensing record of an AS drug between March 2010 and June 2013 were included in the analysis. There was a predominance of male young adults in both the DMARD and anti-TNF groups. Almost half of patients lived in the south and central regions of Minas Gerais State, including the metropolitan area of the capital, 
Belo Horizonte. The mean monthly income per capita ranged from US\$209 in the DMARD group to US\$ 240 in the anti-TNF group (Table 1).

During the follow-up period, $41.0 \%$ of patients initiated treatment with adalimumab, $31.8 \%$ with etanercept, $20.4 \%$ with sulfasalazine, $1.6 \%$ with methotrexate and $5.2 \%$ with infliximab. The average annual drug treatment cost for AS was US\$ 4669,552 (SD US\$ $3385,870)$. There was an increase in the monthly cost and in the number of patients assisted each year during the study period. There was also an increase in the number of dispensations of anti-TNF drugs, which accounted for $88 \%$ of all AS drugs dispensed in 2013. However, the mean cost per dispensation remained similar between 2011 and 2013 (Table 2).

Adalimumab and etanercept were the two largest contributors to the total cost of treatment, representing 52.1 and $41.6 \%$ of the total cost, respectively. The median monthly cost per capita was US\$ 1182 (IQR US\$ 1077-1229) for anti-TNF therapy and US\$ 18 (IQR US\$ 13-22) for treatment with DMARDs. Among the TNF blockers, etanercept was associated with the lowest monthly cost per capita, amounting to US\$ 1067; in comparison, the monthly cost for adalimumab and infliximab was US\$ 1214 and US\$ 1435 , respectively $(p<0.0001$ for all comparisons among anti-TNF drugs). No difference in monthly cost was observed in relation to gender and age (Table 3 ).

Table 1 Baseline characteristics of patients included in the study according to initial therapy during the period 2010-2013 $(N=1251)$

\begin{tabular}{|c|c|c|}
\hline \multirow[t]{2}{*}{ Variables } & \multicolumn{2}{|c|}{ Patient groups according to initial drug therapy } \\
\hline & DMARD $(N=275)$ & Anti-TNF ( \pm DMARD) $(N=976)$ \\
\hline Age (years) & $39.0(30.0-48.0)$ & $41.0(32.0-50.0)$ \\
\hline Male & $169(61.45)$ & $648(66.39)$ \\
\hline \multicolumn{3}{|l|}{ Per capita income $\mathrm{a}^{\mathrm{a}}$} \\
\hline Extremely poor-up to US\$30 & 0 & 0 \\
\hline Poor-up to US\$ 60 & 0 & 0 \\
\hline Vulnerable-up to US\$ 110 & $7(2.75)$ & $10(1.11)$ \\
\hline Lower middle class - up to US\$ 160 & $39(15.29)$ & $63(6.99)$ \\
\hline Average middle class_up to US\$230 & $93(36.47)$ & $284(31.52)$ \\
\hline Upper middle class-up to US\$370 & $76(29.80)$ & $344(38.18)$ \\
\hline Lower-upper class-up to US\$900 & $36(14.12)$ & $161(17.87)$ \\
\hline Upper class-more than US\$900 & $4(1.57)$ & $39(4.33)$ \\
\hline Median (real, R\$) & $209(169-290)$ & $240(196-235)$ \\
\hline
\end{tabular}

Values are presented as the median, with the interquartile range (IQR) in parenthesis or as a number with the percentage in parenthesis

$D M A R D s$ Disease-modifying antirheumatic drugs, $T N F$ tumour necrosis factor, $I Q R$ interquartile range

${ }^{a}$ The income per capita was stratified according to a classification elaborated by the Brazilian Government 
Table 2 Number of patients and cost of drugs during the period 2010-2013 for patients with ankylosing spondylitis

\begin{tabular}{llllllc}
\hline Year & $\begin{array}{l}\text { Number of } \\
\text { patients/month } \\
\text { (mean) }\end{array}$ & $\begin{array}{l}\text { Number of } \\
\text { dispensations/ } \\
\text { month (mean) }\end{array}$ & $\begin{array}{l}\text { Frequency of } \\
\text { dispensation of } \\
\text { TNF blockers (\%) }\end{array}$ & $\begin{array}{l}\text { Total } \\
\text { cost } \\
\text { (US\$) }\end{array}$ & $\begin{array}{l}\text { Mean monthly } \\
\text { cost (US\$) }\end{array}$ & $\begin{array}{l}\text { Mean cost per } \\
\text { dispensation } \\
\text { (US\$) }\end{array}$ \\
\hline $2010^{\mathrm{a}}$ & 16 & 74 & 46.7 & 283,320 & 28,332 & 384 \\
2011 & 50 & 322 & 76.8 & $3,727,350$ & 310,612 & 966 \\
2012 & 79 & 594 & 84.3 & $7,147,403$ & 595,617 & 1003 \\
$2013^{\mathrm{b}}$ & 120 & 841 & 88.0 & $7,520,134$ & 835,571 & 994 \\
\hline
\end{tabular}

${ }^{a}$ Between March and December of 2010

b Between January and September of 2013

Table 3 Therapy cost stratified by drug, gender and age for patients with ankylosing spondylitis

\begin{tabular}{|c|c|c|c|c|c|c|}
\hline Variable & $\begin{array}{l}\text { Number of } \\
\text { patients }\end{array}$ & $\begin{array}{l}\text { Total cost } \\
\text { (US\$) }\end{array}$ & $\begin{array}{l}\text { Percentage } \\
\text { of total cost }\end{array}$ & $\begin{array}{l}\text { Median monthly } \\
\text { cost per capita (US\$) }\end{array}$ & IQR (US\$) & $p$ value \\
\hline \multicolumn{7}{|l|}{ Drug } \\
\hline Adalimumab & 573 & $9,727,968$ & 52.1 & 1214 & $1188-1243$ & $<0.0001^{\mathrm{a}}$ \\
\hline Etanercept & 459 & $7,766,544$ & 41.6 & 1067 & $1033-1098$ & \\
\hline Infliximab & 83 & $1,123,960$ & 6.0 & 1435 & $1345-1504$ & \\
\hline DMARD & 302 & 63,472 & 0.3 & 18 & $13-14$ & \\
\hline \multicolumn{7}{|l|}{ Gender } \\
\hline Male & 816 & $12,591,889$ & 67.4 & 1041 & $1027-1218$ & $0.3425^{b}$ \\
\hline Female & 435 & $6,090,054$ & 32.6 & 1031 & $971-1215$ & \\
\hline \multicolumn{7}{|l|}{ Age (years) } \\
\hline$\leq 41$ & 648 & $8,330,158$ & 44.6 & 1016 & $701-1219$ & $0.9801^{\mathrm{b}}$ \\
\hline$>41$ & 603 & $10,351,785$ & 55.4 & 1048 & $1028-1214$ & \\
\hline
\end{tabular}

$D M A R D s$ Disease-modifying antirheumatic drugs, $I Q R$ interquartile range

a Kruskal-Wallis test

b Mann-Whitney test

\section{DISCUSSION}

In this study we evaluated 1251 patients with AS who had received treatment in Minas Gerais through the SUS during the period 2010-2013. We observed a gender and age distribution similar as to that described in the literature [1]. Most patients included in the study cohort had initiated AS treatment with adalimumab or etanercept, which were the most frequently dispensed drugs during the study period. Few patients had been dispensed DMARDs, which are primarily indicated for peripheral arthritis that affects about $20 \%$ of AS patients $[1,2]$.

The mean monthly cost for AS drug therapy increased from 2010 to 2013 due to an increase in both the number of patients with AS who were treated and the frequency of dispensation of anti-TNF agents. The estimated annual drug cost was US\$ 10 million in 2013, which 
represents $1.7 \%$ of the total Minas Gerais State health budget for prophylactic and therapeutic programmes. The median monthly cost for anti-TNF treatment was US $\$ 1182$ per patient, with etanercept associated with the lowest cost, followed by adalimumab and infliximab. Azevedo et al. [4] estimated that in Brazil, the mean direct cost per month for AS in 2011 was US\$ 1758 per patient and that anti-TNF drugs accounted for $96 \%$ of these expenses.

An observational study using US healthcare claims reported lower costs for etanercept and adalimumab compared to infliximab (US\$ 1279, US\$ 1504 and US\$2002, respectively) between 2005 and 2009 [9]. A similar trend was observed in Spain, and the mean patient-year costs were lower for etanercept $(€ 10,516)$ and adalimumab $(€ 11,934)$ compared to infliximab $(€ 14,235)$ [10]. To the contrary, an Austrian study reported no significant difference among the three TNF blockers, and the monthly cost for drugs per patient was US \$1142 in 2007 (anti-TNF drugs accounted for 95\% of that amount) [11]. In 2010, the National Health Service (NHS) in the UK withdrew infliximab from the list of recommended drugs for AS treatment following new evidence of reduced cost-effectiveness compared to etanercept and adalimumab [12].

In comparison to DMARDs the anti-TNF drugs are very expensive, but the costs of treatment can be balanced with potential long-term cost savings. Since AS is highly prevalent among patients in the most productive age ranges, indirect costs are an important driver of total costs on AS therapy $[4,7]$. Treated patients can expect an improved quality of life and a cessation/modulation of disease progression, potentially decreasing both the direct costs of the disease, including use of other medications and health services, and indirect costs associated with disability, early retirement and sick leave $[3,4,13]$. In Brazil, the annual per capita indirect costs due to AS have been reported to be US\$ 3623 in terms of retirement and US\$ 2451 in terms of sick leave [4]. Nevertheless, another Brazilian study focusing on patients with rheumatic diseases reported that after 6 months of treatment with biological drugs, the quality of life improved in the sample as a whole and in participants with AS. In addition, those participants with the poorest functionality at baseline exhibited a greater improvement in quality of life relative to those participants with a better functional status at baseline [14].

Given the relative lack of head-to-head studies among anti-TNF agents, there is to date no consensus on which drug has the highest efficacy in terms of AS treatment. A 2-year randomised open trial reported no differences between infliximab and etanercept therapy with respect to disease activity, lumbar pain, physical function and inflammation [15]. A meta-analysis of randomised controlled trials showed similar results for adalimumab, etanercept and infliximab, and further analysis applying a mixed treatment comparison corroborates this evidence, as well as observational cohort studies [16-20]. Based on these results, both Brazilian and international recommendations do not indicate a preference for any one of the drugs available for the treatment of axial disease manifestations $[5,6]$. However, drug cost should be one criterion for the choice of appropriate therapy, and-according to our results-etanercept would seem to be the least expensive of the available drugs, possibly providing a suitable option. A further analysis should involve a cost-effectiveness approach to compare etanercept and golimumab, a new anti-TNF drug that has not been incorporated into the SUS. 
One limitation of our study involved the use of administrative databases. Data on other medications used to treat AS, including NSAIDs, were not available in the administrative databases used in this study. Moreover, the APAC/SIA is a database that contains records of the production and payment of outpatient procedures and has limited clinical data. However, other studies have demonstrated the validity of these databases in tracing the trajectory of health assistance beneficiaries in Brazil [21, 22]. The strength of our study is that we used a large community-based sample to describe drug utilisation and to estimate drug costs in AS patients in a real-world setting. Therefore, we believe that our results can be applied to improve economic assessment as well as to implement and evaluate public health policies related to the treatment of AS.

\section{CONCLUSION}

Patients with AS in Minas Gerais, Brazil, were most often prescribed adalimumab and etanercept between March 2010 and September 2013. The results indicate an increase in the coverage of the AS therapy program in the Brazilian Public Health System and a growing demand for anti-TNF agents. Therapy with etanercept was associated with a lower cost per patient than adalimumab and infliximab. This study highlights the economic burden of treating AS patients and provides data for further cost-effectiveness analysis.

\section{ACKNOWLEDGMENTS}

The study was funded by the National Counsel of Technological and Scientific Development (CNPq) (Grant Number 564778/2010-9). All authors meet the International Committee of Medical Journal Editors (ICMJE) criteria for authorship for this manuscript, take responsibility for the integrity of the work as a whole and have given final approval for the version to be published. This study was supported by the National Council for Scientific and Technological Development (CNPq) and the Minas Gerais State Research Foundation (Fapemig). The authors thanks the Research Group on Pharmacoepidemiology and the Research Group on Health Economics of the Federal University of Minas Gerais for making available the data used in the study. M. Amaral de Ávila Machado has received scholarships from the Minas Gerais State Research Foundation (Fapemig) and the Brazilian Federal Agency for the Support and Evaluation of Graduate Education (Capes, 8793-13-1). F. de Assis Acurcio has received scholarship from the Brazilian Federal Agency for the Support and Evaluation of Graduate Education (Capes, BEX 2276/14-3).

Disclosures. Marina Amaral de Ávila Machado, Felipe Ferre, Cristiano Soares de Moura, Alessandra Maciel Almeida, Eli Iola Gurgel Andrade, Mariângela Leal Cherchiglia and Francisco de Assis Acurcio have nothing to disclose.

Compliance with Ethics Guidelines. This article does not contain any new studies with human or animal subjects performed by any of the authors.

Open Access. This article is distributed under the terms of the Creative Commons Attribution-NonCommercial 4.0 International License (http://creativecommons.org/licenses/ by-nc/4.0/), which permits any noncommercial use, distribution, and reproduction in any 
medium, provided you give appropriate credit to the original author(s) and the source, provide a link to the Creative Commons license, and indicate if changes were made.

\section{REFERENCES}

1. Braun J, Sieper J. Ankylosing spondylitis. Lancet. 2007;369(9570):1379-90.

2. Boonen A, van der Linden SM. The burden of ankylosing spondylitis. J Rheumatol Suppl. 2006;78:4-11.

3. Boonen A, van der Heijde D, Landewé R, Spoorenberg A, Schouten H, Rutten-van Mölken M, Guillemin F, Dougados M, Mielants H, de Vlam $\mathrm{K}$, van der van der Tempel $\mathrm{H}$, Linden $\mathrm{S}$. Work status and productivity costs due to ankylosing spondylitis: comparison of three European countries. Ann Rheum Dis. 2002;61(5):429-37.

4. Azevedo VF, Rossetto CN, Lorencetti PG, Tramontin MY, Fornazari B, Araújo DV. Indirect and direct costs of treating patients with ankylosing spondylitis in the Brazilian public health system. Rev Bras Reumatol. 2016;56(2):131-7. doi:10.1016/ j.rbr.2015.06.002.

5. Braun J, van den Berg R, Baraliakos X, Boehm H, Burgos-Vargas R, Collantes-Estevez E, Dagfinrud H, Dijkmans B, Dougados M, Emery P, Geher P, Hammoudeh $\mathrm{M}$, Inman RD, Jongkees $\mathrm{M}$, Khan MA, Kiltz U, Kvien T, Leirisalo-Repo M, Maksymowych WP, Olivieri I, Pavelka K, Sieper J, Stanislawska-Biernat E, Wendling D, Ozgocmen S, van Drogen C, van Royen B, van der Heijde D. 2010 update of the ASAS/EULAR recommendations for the management of ankylosing spondylitis. Ann Rheum Dis. 2011;70(6):896-904.

6. Brasil. Ministério da Saúde Secretaria de Atenção à Saúde. Portaria $\mathrm{n}^{\circ}$ 640, de 24 de julho de 2014 . Aprova o Protocolo Clínico e Diretrizes Terapêuticas da Espondilite Ancilosante. 2014. Available at: http://portalsaude.saude.gov.br/images/pdf/2014/ julho/25/pcdt-espondilite-ancilosante-2014.pdf. Accessed 22 Dec 2014.

7. Palla I, Trieste L, Tani C, Talarico R, Cortesi PA, Mosca M, Turchetti G. A systematic literature review of the economic impact of ankylosing spondylitis. Clin Exp Rheumatol. 2012;30(4) Suppl 73:S136-S141.

8. Paim J, Travassos C, Almeida C, Bahia L, Macinko J. The Brazilian health system: history, advances, and challenges. Lancet. 2011;377(9779):1778-97.
9. Bonafede MM, Gandra SR, Watson C, Princic N, Fox KM. Cost per treated patient for etanercept, adalimumab, and infliximab across adult indications: a claims analysis. Adv Ther. 2012;29(3):234-48.

10. Escudero-Vilaplana V, Ramírez-Herráiz E, Alañón-Plaza E, Trovato-López N, García-Vicuña R, Carreño-Pérez L, Morell-Baladrón A, Sanjurjo-Sáez M. Efficiency of adalimumab, etanercept and infliximab in ankylosing spondylitis in clinical practice. Int J Clin Pharm. 2015;37(5):808-14. doi:10.1007/s11096-015-0124-1.

11. Nell-Duxneuner V, Schroeder Y, Reichardt B, Bucsics A. The use of TNF-inhibitors in ankylosing spondylitis in Austria from 2007 to 2009 - a retrospective analysis. Int J Clin Pharmacol Ther. 2012;50(12):867-72.

12. National Institute for Health and Clinical Excellence (NICE). Technology appraisal guidance 143. Adalimumab, etanercept and infliximab for ankylosing spondylitis. Review date October 2010. Available at: https://www.nice.org.uk/guidance/ ta143. Accessed 15 Jan 2016.

13. Strömbeck B, Englund M, Bremander A, Jacobsson LT, Kedza L, Kobelt G, Petersson IF. Cost of illness from the public payers' perspective in patients with ankylosing spondylitis in rheumatological care. J Rheumatol. 2010;37(11):2348-55. doi:10.3899/ jrheum.100099.

14. Oliveira Junior HA, dos Santos JB, Acurcio FA, Almeida AM, Kakehasi AM, Alvares, de Carvalho LFD, Cherchiglia ML. Poorer functionality is related to better quality of life response following the use of biological drugs: 6-month outcomes in a prospective cohort from the Public Health System (Sistema unico de Saude), Minas Gerais, Brazil. Expert Rev Pharmacoecon Outcomes Res. 2015;15(3):403-12. doi:10.1586/14737167.2015. 1003367 .

15. Giardina AR, Ferrante A, Ciccia F, Impastato R, Miceli MC, Principato A, Triolo G. A 2-year comparative open label randomized study of efficacy and safety of etanercept and infliximab in patients with ankylosing spondylitis. Rheumatol Int. 2010;30(11):1437-40.

16. Machado MA, Barbosa MM, Almeida AM, de Araújo VE, Kakehasi AM, Andrade EI, Cherchiglia ML, Acurcio Fde A. Treatment of ankylosing spondylitis with TNF blockers: a meta-analysis. Rheumatol Int. 2013;33(9):2199-213.

17. Migliore A, Bizzi E, Bernardi M, Diamanti AP, Laganà B, Petrella L. Indirect comparison between subcutaneous biologic agents in ankylosing spondylitis. Clin Drug Investig. 2015;35(1):23-9. 
18. Spadaro A, Lubrano E, Marchesoni A, D'Angelo S, Ramonda R, Addimanda O, Perrotta FM, Olivieri I, Punzi L, Salvarani C. Remission in ankylosing spondylitis treated with anti-TNF- $\alpha$ drugs: a national multicentre study. Rheumatology (Oxford). 2013;52(10):1914-9.

19. Kristensen LE, Petersson IF, Geborek P, Jöud A, Saxne T, Jacobsson LT, Englund M. Sick leave in patients with ankylosing spondylitis before and after anti-TNF therapy: a population-based cohort study. Rheumatology (Oxford). 2012;51(2):243-9.

20. Arends S, Brouwer E, van der Veer E, Groen $\mathrm{H}$, Leijsma MK, Houtman PM, Th A Jansen TL, Kallenberg CG, Spoorenberg A. Baseline predictors of response and discontinuation of tumor necrosis factor-alpha blocking therapy in ankylosing spondylitis: a prospective longitudinal observational cohort study. Arthritis Res Ther. 2011;13(3):R94.

21. Acurcio FA, Brandão CM, Guerra AA Jr, Cherchiglia ML, Andrade EI, Almeida AM, da Silva GD, de Queiroz OV, Faleiros DR. Perfil demográfico e epidemiológico dos usuários de medicamentos de alto custo no Sistema Único de Saúde. Rev bras estud popul. 2009;26(2):263-82.

22. Brandão CM, Guerra AA Jr, Cherchiglia ML, Andrade EI, Almeida AM, da Silva GD, de Queiroz OV, Faleiros DR, Acurcio Fde A. Expenses of the Brazilian Ministry of Health for high-cost drugs: a demographic and clinical analysis. Value Health. 2011;14(5) Suppl 1:S71-S77. 